Sonic Scope: New Approaches to Audiovisual Culture

\title{
Covid-19 as a Catalyst For The Enculturation of Online Video Performance: The Online Stage During The Coronavirus Lockdown
}

Taran Harris

Published on: Feb 15, 2021

DOI: $10.21428 / 66 f 840 a 4.24608 \mathrm{bfd}$

License: Creative Commons Attribution 4.0 International License (CC-BY 4.0). 


\section{ABSTRACT}

Covid-19 as a Catalyst For The Enculturation of Online Video Performance: The Online Stage During The Coronavirus Lockdown

Taran Harris, University of Liverpool

Covid-19 has seen an increase in particular types of performance within the digital space of social media. Whether live or pre-recorded, the social media news feed has been flooded with creative musical endeavours, and has pulled into focus the framing of the digital space as a performance stage. I term this internet-based, performance space the 'online stage,' which, as I argue, has undergone a protracted process of enculturation throughout the 21st-century, thereby legitimising online performance amongst increasingly varied demographics. Whilst the enculturation of the online stage is not solely attributable to the Covid-19 lockdowns, I suggest that this process was exacerbated by the restraints and impositions of Covid-19 that have acted as a catalyst for both the production and consumption of online performance.

With a surge of working musicians turning to the online stage in search of a much-needed source of income, along with a number of major festivals employing it as their main venue, the online stage received a dramatic increase in prominence through sudden social-media ubiquity and an almost overnight adoption by media institutions. As such, the online stage gained a status of enculturation among a prominent section of the UK out of the necessity for live entertainment. This paper analyses the factors which built towards Covid19 accelerating this enculturation process over such a contracted and pressurised period of time.

\section{Introduction}

The summer of 2020 saw the United Kingdom enter a further three weeks of lockdown to battle an unprecedented virus pandemic, having already undergone four weeks of household quarantine. During this time, Covid-19 created a strange new world and its impact continues to be felt across countless professions, not least those within the entertainment industry. In light of the statemandated cessation of non-essential activities and a sudden increase in the need to work from home, the life of a performing musician has been seriously affected, while a digital landscape that was already problematising ideas of liveness and reception theories has changed gear dramatically. Covid19 has seen an increase in particular types of performance within the digital space of social media. Whether live or pre-recorded, the social media news feed has been flooded with creative musical endeavours, and has pulled into focus the framing of the digital space as a performance stage. I term this internet-based, performance space the "online stage," which, as I shall argue, has undergone a 
protracted process of enculturation throughout the $21^{\text {st }}$-century, thereby legitimising online performance amongst increasingly varied demographics. Whilst the enculturation of the online stage is not solely attributable to the Covid-19 lockdowns, I suggest that this process was exacerbated by the restraints and impositions of Covid-19.

In this article, I will explore how the UK-wide lockdown has been the catalyst for a dramatically accelerated enculturation process for digital liveness, a process that has been underway for a number of years and has resulted in the legitimation of the online stage as a viable alternative to more traditional venue spaces. The term 'digital liveness' is premised on Philip Auslander's assertion that "what counts culturally as live experience changes over time in relation to technological change," and in this article encompasses music's online presence as digital content and online video.. Online video can take many different forms, from music videos and pre-recorded performances to live streamed events. For this article, I am dealing with videos that show actual performance on screen, be they prerecorded or live, rather than music videos. As I will argue, these videos, regardless of their temporal status, are expressions of digital liveness.

Due to the varying levels and styles of government action being taken across the world in response to Covid-19, it would be problematic and unwieldy to attempt to describe the impacts of the pandemic everywhere. Instead, I am therefore focussing on the UK music scene. By the very nature of the medium, audiences of online content are not limited to the UK, but by limiting my remit I hope to avoid confusion with world-wide restrictions. Additionally, it is far from my intention to suggest that online video is a new phenomenon in music, or to ignore the huge amount of people who have been enjoying musical content on the online stage for years. Rather, in recent years video sharing websites such as YouTube and Vimeo have increasingly become the medium by which a great deal of young people choose to listen to their music, with video streaming sites accounting for $47 \%$ of all streamed music across the world, according to the 2019 Music Listening Report. $\underline{2}$

I will firstly outline the separate processes of naturalisation and enculturation, before setting out a conceptual model of the digital landscape in the pre- and post-Covid-19 worlds. I shall argue that the legitimacy and authenticity of the online stage as a performance space has accelerated through naturalisation and enculturation, drawing upon the familiar enculturation journey of television media, before analysing the current process in action, using contemporary examples from online platforms. $\underline{3}$ As will become evident, the legitimacy of the online stage comes from two directions: the authenticity of the online, amateur-professional culture of YouTube; and the necessary professional aspects of the business of performing as a career in the brick and mortar industry. This delicate balance of amateur and professional presentation styles lends the online stage a feeling of enculturated legitimacy through a blending of authenticity and professionalism, put in place due to the unique pressures of Covid-19. 


\section{Naturalisation vs. Enculturation}

There are numerous ways to document technologies' enculturation within popular music cultures. The terms 'naturalisation' and 'enculturation' have often been used in academic literature interchangeably, with scholars using them to posit theories regarding the integration of technology into the listening habits of cultures, as time and ubiquity normalises its use. $\underline{4}$ Sarah Thornton, however, regards naturalisation and enculturation as two separate, but linked, processes, defining naturalisation as the process by which the increasingly ubiquitous use of a technology allows its use, over time, to go unnoticed by the listening public. $\frac{5}{}$ Naturalisation, then, is a process of subconscious acclimatisation culminating in the point at which the everyday normality and ubiquity of any given technology is signified by the lack of conscious attention that it receives. Enculturation, meanwhile, signifies a more active form of cultural acceptance which, Thornton argues, culminates with the cultural authentication of the technology in question; that is to say, the technology itself is not only integrated and naturalised amongst a population, but its usage is understood and actively accepted by its users. The enculturation process is complex and should not be understood as an instantaneous occurrence among a homogenous audience, but rather occurs over a period of time and potentially amongst multiple audiences.

Building on Thornton's arguments, I suggest that enculturation relies on the authenticator (in this case the listening public) both accepting the value of a given technology within a given musical context and possessing some knowledge of its use. In recognising a marked difference between naturalisation and enculturation, we can begin to acknowledge the fact that a technology becoming an enculturated part of a continuing musical culture marks a more active form of cultural acceptance beyond becoming naturalised and common within popular music listening. This distinction separates the subconscious acclimatisation of naturalisation and the cultural authentication of enculturation.

Regarding digital liveness - defined by Auslander as "the effect of liveness in our interactions with computers and virtual entities" - there are a few ways in which the audience's knowledge of the process could be lacking, thereby diminishing its potential to become fully enculturated. $\underline{6}$ For example, with regards to recorded content, a common question may be 'how many takes was this?' whilst a more musically literate audience may ask 'are they using technology to aid this performance?' Of course, a great deal of the audience will not have access to the answers to these questions. As such, while authentication is being made at all times, it is done so with limited access to relevant information regarding a recording's use of technology. This would suggest that, following the acceptance of a technology's usage, enculturation can occur despite limited information on its implementation in any given recording. The enculturation process is complete by authentication and therefore corresponds to 
the personal nature of authenticity established by Allan Moore, who states that "academic consideration of authenticity should ... focus on the reasons [the audience] might have for finding, or failing to find, a particular performance authentic."푸 For instance: one may have a certain level of knowledge about a technology and, based on that knowledge, authenticate and accept that technology. For this audience member, enculturation has occurred and may subsequently be re-evaluated based on new evidence.

To return to my core thesis regarding the online stage: where naturalisation is concerned, it could be a relatively quick process for it to feel normal that social media platforms are a place to find natural, real, or behind-the-scenes content. However, when considering enculturation, the question may change based on the audience's level of understanding and their acceptance of the technology used. To put it simply, the online stage has gradually become ubiquitous within our daily social media lives, and through its current accelerated enculturation, the audience may begin to see online platforms as a genuine performance venue. This is already evident, with Facebook reporting huge spikes in live streaming usage during the lockdown. $\underline{8}$

The distinction between naturalisation and enculturation is important for this discussion as they stand for different levels of agency, which can in turn translate to different levels of longevity for the audience going forward. Nick Couldry's theorisation of liveness distinguishes the term from a more traditional understanding of 'live,' defining “online liveness: [as] social co-presence" that is "simply an extension of traditional liveness." 9 Couldry therefore posits liveness as integrally linked with social interaction, while the importance of the physical expression and context of performance is diminished. In the years since Couldry's article, the presence of online liveness, and by extension the enculturation of the online stage as a legitimate performance space, has increased immeasurably. We must therefore find a way to conflate the meanings of Couldry's online liveness and mediated liveness when it comes to the vastly increased levels of performance happening online.

As discussed above, Auslander introduced us to the cultural idea of liveness, as well as the notion that "the live event is 'real' and that mediatized events are secondary and somehow artificial reproductions of the real," before arguing that television was able to maintain its association with liveness, even long after the majority of programming became pre-recorded. $\underline{10}$ Rick Altman surmised this as such, stating that "whether the events transmitted by television are live or not, the television experience itself is ... sensed as live by the home viewing audience." $\underline{11}$ In essence, through the long process of enculturation, television grew to such a level of legitimacy that its processes were not seen by the general audience as being a transformative form of mediatisation. This, combined with television's culture of live broadcast, gave it a feeling of liveness unequal to its edited and mediatised reality. This concept can be transported forward several decades to combine with the culture of the amateur, cultivated through the emergence of video platforms such as YouTube. This in turn has 
brought the culture of recorded-liveness up-to-date and suggests that liveness has a meaning more akin to the authenticity associated with live performance, rather than a necessity for actual live performance itself. The added factor that online video contributes is that of Web 2.0 or participatory culture, a web model that relies on user-created content, user-led dissemination, and user-led feedback and discussion.

\section{YouTube as a Participatory Culture}

Social media is inherently tied to connection and community, and the same is true for video sharing platforms such as YouTube. Since its founding in 2005, YouTube's conceptual and visual template has impressed itself across all corners of the internet, bearing the hallmarks of Web 2.0's major developments in user-generated and mediated content. Not only did these developments allow for democratised distribution of content, but it enabled this content to be curated by the audience's interaction through likes and comments, a style of content provision and consumption that has influenced various social media platforms. This has served as a contextual layer for the authenticity and immediacy of user-generated content for social media platforms such as Facebook to reference in their later forays into video sharing, benefitting from the artefacts of liveness and authenticity left by YouTube's early focus on amateur content provision. This historical context helps to construct the visual conventions and authenticity paradigm which is accelerated by Covid-19's use of the online stage as a site for liveness and professional performance.

YouTube, as part of the framework of participatory culture, cultivates its image as a platform which places musical content within a culture of what Jean Burgess and Joshua Green term "vernacular creativity." 12 Burgess coined the term in 2006 to describe "creative practices that emerge from highly particular and non-elite social contexts and communicative conventions," with the meaning of vernacular being "used to distinguish 'everyday' language from institutional of official modes of expression." $\underline{13}$ In this, YouTube, along with Facebook and Instagram, is able to foster a feeling of community amongst its users. There is a great deal of academic study into YouTube and participatory culture, and, as such, YouTube may appear to be the best case study when examining participatory culture as a platform for liveness and authenticity. $\underline{\underline{14}}$ However, these studies can also prove useful in examining other social media platforms that experienced a boom in usage during the initial months of the Covid-19 pandemic.

Web 2.0, a platform-based and customer-led approach to the internet revolving around "harnessing collective intelligence," is the name given to the secondary stage of web development, based largely on its capacity for user interactivity. $\underline{15}$ Taken from Terry Flew's work in New Media and drawing on the 
work of Michel de Certeau, Henry Jenkins "adapted the idea to evolving media technology" to examine how it "transforms the experience of media consumption into production of new texts, indeed of a new culture and a new community." 16 Jean Burgess and Joshua Green, meanwhile, have argued that "participatory culture is YouTube's core business. The cultural logics of community, openness, and authenticity are embedded in the YouTube platform and brand at all scales of commerciality, from everyday documentation through all those star YouTubers with six-figure incomes, billions of views and millions of subscribers [emphasis in original]."17 This is arguably due to YouTube having cultivated an aesthetic that puts reality, normality and the idea of an 'amateur-professional' at its core. By using the term 'amateur-professional,' I aim to illustrate the kind of figure who is an expert at what they do, but not controlled or mediatised by a corporation; perhaps the digital equivalent of an independent artist, un-beholden to record labels or corporations. This is not to say that these creators do not leverage the business models and rules of platform-based businesses, conforming to certain rules, rather that the apparent situation to the audience is one of independence.

The technological mediation of the YouTube amateur-professional has reached a point of naturalisation, forcing the audience to make sense of how the live performance interacts with the mediatisation to which they have become accustomed. While the presence of editing techniques such as jump cuts and time-lapse footage are obvious signs of mediation, the democratisation of technology, aided by the low costs of content creation, has meant that such techniques may now be accepted and enculturated by a large portion of a creator's audience. As such, these processes are no longer seen as mediation from an outside source, but are understood as a stylistic choice by the performer.

YouTube can be understood as a platform where the democratisation of technology has allowed a renaissance of independent artistry; where the rise of the amateur has attached a level of ambiguity between the worlds of professional and hobbyist, with each world lending an essence of itself to the other. With the blurring of boundaries created by this democratisation, it becomes difficult to discuss professional and amateur content as binaries. YouTube's emphasis on vernacular creativity, surmised by its erstwhile tagline "Broadcast Yourself," intersects with the "[YouTube] oriented towards professional production," resulting in a complex content identity on the platform: a haze of amateurism, professionalism, mediatisation and candid self-expression. $\underline{18}$ As YouTube's content is largely presented to us as unmediated by corporate interests, the online audience may be more likely to trust and applaud the work of what Andrew Keen describes as the "noble amateur." 19 Just as one may trust the unfettered TripAdvisor review over a review found in a newspaper with sponsors and set brand opinions and affiliations, Keen cites this inclination toward unmediated content as "the great seduction. The Web 2.0 revolution has peddled the promise of bringing more truth to more people more depth of information, more global perspective, more unbiased opinion from dispassionate observers." $\underline{20}$ This somewhat idealistic view of the "dispassionate observer" is predicated on the 
assumption that the content that comes as user-generated is therefore inherently unmediated. It is of course impossible to know if this an assumption that is made en-masse and at all times, but this is one example of how YouTube and social media function culturally.

One possible expectation is that amateur musicians' online videos are pure presentations of talent, unmediated and representative of the most plain form of authenticity available to a modern audience. Here, we can see that Web 2.0 platforms, such as YouTube, Instagram and Facebook, present what has been termed by Peter Nagy and Gina Neff as "imagined affordances." $\underline{21}$ As Nagy and Neff assert, these imagined affordances "emerge between users' perceptions, attitudes, and expectations; between the materiality and functionality of technologies; and between the intentions and perceptions of designers." 22 Such instances serve to connect any projection of liveness from the performer to the reception of liveness from the audience, presenting any obvious mediatisation, such as video edits, as affordances in a technologically democratised society.

As stated above, YouTube has promoted itself as a locus of unmediated amateur content since its inception. Burgess and Green, in their monograph YouTube: Online Video and Participatory Culture, explain YouTube's approach to amateur and professional content, stating that "there have always been two simultaneously operating YouTubes: one oriented towards professional production ... and one more interested in sheer scale and near-ubiquity, providing a platform for everyday expression, vernacular creativity and community formation. The two YouTubes have never really been separate, and are increasingly entangled." 23 The perceived liveness of the online stage partly survives as an artefact from earlier forms of media, as I argued earlier, yet YouTube is a prime example of how live and pre-recorded content influence each other in their presentations of liveness. The expectation from such sites could therefore be seen as a hangover of liveness from YouTube's initial "Broadcast Yourself" concept: up-to-the-minute updates from your daily life. Put simply, social media's overarching attraction for users is immediacy and the integration of various strands of everyday life in one platform. To tie the immediacy and candid culture of the platform to lockdown provides us with an intensification of the potential for the online stage as an alternative to venue-based performance. The accompanying half of the construct of legitimacy for the online stage comes from a feeling of professionalism and structure, something that I shall cover in the next section.

Music is a central part of this for a lot of people. The catalyst for such enculturation is Instagram and its parent company Facebook's investment in the infrastructure of livestreaming over the last few years. It is therefore important to note that the naturalisation of digital liveness has not happened by accident, but as an active step from a corporation whose aim is to incorporate every form of engaging content into their platform. Social media's place as an online venue was already in the process of naturalisation and enculturation, a process that has taken several years; however, Covid-19's unique circumstances have augmented and accelerated this for many people. 


\section{Live Streamed Gigs - All the World's a Stage}

YouTube streamed its first ever live content in 2012 for the USA presidential debates, in partnership with $\mathrm{ABC}$ news. $\underline{24}$ Since then, we have seen live streaming become a naturalised form of online media, similar to that of live television but with the addition of a perceived personal agency from the creatorperformer. As such, we attach a degree of authenticity to it as it builds upon the immediacy of the platform granted by the apparently unmediated essence of YouTube, and social media more broadly. Be it the non-curated, user-generated content of YouTube, or Facebook's "What are you doing right now?" status updates, a perceived lack of interference strengthens feelings of authenticity. $\underline{25}$ Simon Frith neatly surmises this, asserting that "A plays to B and the less technology lies between them the closer they are, the more honest their relationship and the fewer the opportunities for manipulation and falsehoods." $\underline{26}$ This suggests that the concept of a live stream could further legitimise online platforms as performance spaces. Yet, online media presents itself as a double-edged sword: with live content promising unfettered, authentic performance, much social media content is shrouded behind the uneasy world of filtered images and fake news. Despite this, a 2020 study showed that 'selfies' that make use of popular filters garnered fewer likes from other social media users, since "selfpresentation that involves manipulating one's appearance is no longer considered authentic." $\underline{27}$ It could be said that Instagram Live, the app's feature enabling live performance, acts as music's demonstrative equivalent to the popular Twitter and Instagram hashtag trends \#nofilter and \#nomakeupselfie presenting unmediated content, direct from source. While the reality could be that behind these performances lie a film crew, script and live staging or manipulation software, the word 'live,' in addition to the audience's assumptions about the casual and often phone-based culture of Instagram, projects a certain picture of authenticity.

\section{The Covid-19 Home Environment}

When the UK government announced a nation-wide lockdown on $23^{\text {rd }}$ March, it indicated a clearcut and indefinite postponement to the entertainment industry as we have come to know it. $\underline{28}$ With social activity an impossibility, the available performance spaces for working musicians and amateurs alike became limited to the realms of television, radio and internet platforms, while, concurrently, a sudden need for entertaining content arose within the rest of the UK population. To examine the effects of the Covid-19 on online content's legitimacy, it is important here to note the needs and 
pressures of the two different players in this situation: the quarantined performers and the quarantined audience.

\section{The Quarantined Performer}

In order to gain the legitimacy of a traditional performance venue, the online stage must perform the practical functions that a real world stage provides. This is primarily its function as a place of work. The shift of social media's function from personal to professional, a shift that has been well under way for many years, has suddenly become one of necessity rather than choice, and has thrust its potential for earnings directly under the nose of the great majority of working musicians who were yet to fully embrace the online stage as a viable alternative. This potential income has largely addressed one of the most concerning issues that has affected musicians during lockdown: the loss of earnings from touring.

To earn from online media is not a new concept. Rather, since it began to monetise videos in 2008 , YouTube has created multiple millionaires. $\underline{29}$ In the case of online performances, financial earnings are not generally derived from advertising revenue, as is often the case among YouTube users, but rather from a more straightforward, money-for-service transaction. From the week immediately prior to lockdown, whilst the British public were advised to "avoid gatherings and crowded places, such as pubs, clubs and theatres," it was certain that the entertainment industry, especially that of the touring musician, was in danger and immediate need of a new income stream. $\frac{30}{}$ During the lockdown, however, live streaming quickly stepped into the void created by shuttered venues by virtue of being the only available option; one that could reach a good proportion of one's online friendship circle with the minimum of effort and/or rule breaking. These performances soon started to become timed events, with the crucial addition of the Paypal Tip Jar allowing viewers to donate in return for these live concerts. One such example can be seen in the accompanying text from a live stream by Liverpool country musician Ethan Allen:

Hi guys, I will be doing a FACEBOOK LIVE stream tonight at 7pm to kick off your evening.

I have set up a PayPal virtual tip jar.

As a self employed musician it's going to be a long time before I can play gigs live again. I want to entertain you all but I also want to feed the fambo.

So, start listing requests throughout the day and don't forget to tip.

See you at 7 bells live from the ranch. $\underline{31}$ 
By presenting this donation link with their performance, the live stream performance scenario gets shifted from a virtual outlet of creativity to virtual busking. To contextualise each level of online professional performance with its real world equivalent allows us to see the online stage's journey through enculturation more easily. However, perhaps somewhat predictably, the situation quickly developed. To continue with Allen's live streamed performance as our example, it is enlightening to discuss the audiovisual and social experience that it created.

Firstly of note is how Allen presents the performance (see figure 1). Sitting on a stool, wearing a black button up shirt and a fedora, this is not being presented as an impromptu piece of content for social media. Allen presented himself as he would for a performance in a physical venue, against a neutral and un-cluttered backdrop, and proceeded to provide a performance of 2 hours and 49 minutes to approximately 1500 viewers, whilst verbally interacting with the crowd's 926 comments as the show progressed. $\underline{32}$ Allen, who had previously used social media to live stream individual songs or to advertise his performances at more traditional venues, took to this medium in a much more active way due to the lockdowns, and therefore made the experience as true to the real life gigging experience as possible. The formalities of performance attire, full length set list and the opportunity to tip the artist serves to legitimise this live stream as an event, while Allen's chatter with the virtual crowd interacts with the online liveness of social media, adding to the performance atmosphere.



The designation of a set performance time and schedule, using Facebook's event creation tools, quickly served to legitimise the format in the style of a ticketed event. This is a development that mirrors the long running tradition of scheduled entertainment, putting the online stage in parallel 
with theatre shows, ticketed gigs, and evenings at live music bars in the now-deserted city centres. The deluge of online performances quickly led to music promoters creating virtual festivals such as Coronapolooza, while Radio l's Big Weekend 2020 turned virtual for the first time. $\underline{33}$ The most elaborate and notable form of this was the Global Citizen's One World: Together at Home, which featured performances from artists such as Lady Gaga, Paul McCartney, Billie Eilish and many others. $\underline{34}$ This marks an important point for the online stage in terms of its enculturation, as the event shows the incorporation of the online stage into established broadcasting institutions such as the BBC. The One World concert organisers, meanwhile, were able to capitalise on the current social phenomenon of the online stage by spreading their content across a mixture of online and traditional broadcast platforms, streaming a "six-hour 'pre-show' ... on Facebook, Instagram, Twitter and YouTube; followed by the main two-hour broadcast, which was shown simultaneously by all three of the main US TV networks." 35 This cross-platform scheduling would also have a positive effect on how other online performances were perceived in the days and weeks after broadcast, as they gave the performance and filming styles the legitimacy of traditional media.

This development from online live performance, from busking to scheduled performances at corporate virtual festivals, clearly illustrates the pressure cooker environment that Covid-19 has imposed upon the UK music scene. Developing from the necessity of earning a living, the virtual performance space has developed from its relative infancy to become the dominant performance format in use at every level of the industry within a matter of weeks. Typically, you may expect that with such a dramatic change, once the lockdown is lifted enough to allow such leisure activities as music performance to recommence in the traditional manner, that the enculturation status of the online stage may dissipate as quickly as it arrived. The power of technological enculturation may well be linked to the length of time it takes to achieve. The lifting of lockdown has not been nearly clean-cut enough for this to be a measurable factor. Instead, the UK entertainment industry has found itself in limbo, offering no stability for performers hovering between physical and digital spaces. Whilst the issue of lost earnings was arguably the most fundamental factor in the enculturation of online performance, lockdown also provided performers a valuable opportunity: time. When combined with the democratisation of technology, this allowed for a further enculturation of modern audio technology.

Online social media feeds have had a lot more to offer than live streams of musical performances during the weeks and months of lockdown. Other available content has relied more on the wealth of technology available, at varying levels of affordability, to the majority of the UK's population. The act of creating multilayered and multi-camera, single-performer videos has been the remit of a sizeable number of content-creators for many years. Yet it has not been immune to lockdown, increasing the quantity of content and the frequency at which it appears. In much the same way that live streaming has proven to be a monetary opportunity for gigging musicians (though perhaps not a viable long-term 
alternative), the more widespread act of musical content creation has the bonuses of filling the increased amounts of free time, acting as an outlet for musical creativity, and providing content, whether promotional or otherwise. The enculturation issues that stem from this content involve marrying the audience's increased contact with modern recording technologies and the content platform's aforementioned amateur culture. As is the issue of technological transparency within popular music, it is similarly impossible to know which, and to what extent, technologies have been used within pre-recorded online video. Here is where the distinction between naturalisation and enculturation becomes important, as lockdown's impact on technologically mediated content has aided in speeding up the naturalisation and enculturation of such visually obvious technologies as multitracking and virtual performance spaces. It is more difficult to determine its impact on the enculturation stage of the process when it comes to the invisible use of manipulation effects such as Auto-Tune. This conclusion is due to enculturation's requirement for acceptance based on varied levels of knowledge of use. This potentially allows for the enculturation of technologies among some audiences, whilst others may refuse to accept these same technologies based on their own understanding of what they mean to the authenticity of the performance. It is the wealth of time that performers were afforded during lockdown that has allowed both the quality of production and potential for manipulated performance to grow. With hours of house-bound recording and practice, the increased quality and quantity of online content was integral to the increased prevalence and prominence of performance on the online stage.

\section{The Quarantined Audience - Primed for Entertainment}

When discussing performance, it is important to also give consideration to the audience, as a truly rounded analysis regards both the intention and the reception. A Covid-19 audience is one to whom digital media and social media is a common part of every day life; they are digital natives by necessity, whilst we are stuck at home by government mandate. With furloughed workers restricted to their homes, the country's media consumption, including time spent on social media and streaming videos, has been exacerbated. $\underline{36}$ As stated earlier, online video content is nearing the end of its enculturation journey. For many, especially younger generations, it has concluded. Yet, where increased content creation meets increased content consumption, the online stage dramatically increased its audience and widened its demographic as a destination venue to watch both live and pre-recorded musical performance.

With artists and promoters organising timed live events and releasing frequent content on their pages and channels, the online stage is quickly joining the ranks of more traditional entertainment venues, such as music halls, theatres and cinemas, as a place that people actively go for their 
entertainment fix. For the artist, the presentation of the online platform as a performance space is vital in shaping how the audience perceive it. This can be evidenced in the description for The Voice runner-up Callum McMorran's scheduled live stream, which reads almost like professional advertisement copy:

The Sunday Sessions!

Live music direct to your living room!

Callum is doing live sessions from 7:30pm every Sunday evening and all proceeds will go to the NHS Together Foundation!

Perfect Sunday night listening!

Requests welcome and tracks will be played from the new EP ‘ 400 miles from home’!

Join us!

And remember, if you can donate all proceeds are going direct to the NHS Charities Together https://www.justgiving.com/fundraising/callummac

Thank you! $\underline{37}$

These performances appear presented as a residency for McMorran on the online stage, a space deemed legitimate enough to serve as the venue for a scheduled event, but also as an advertising platform for a new product. In place of McMorran's more conventional weekly residencies at physical venues, this online live event encapsulates all of the professionalism and advertising opportunity that traditional giggling would have entailed in a pre-lockdown scenario.

This presentation and marketing of online performance has been warmly received by fans, who can be seen planning these events into their schedules and entertainment line-up. This is evidenced in the comments section of the announcement of online performances, such as Ethan Allen's $3^{\text {rd }}$ April Facebook event, where Lillian Odell commented "Looking forward to tonight," and on Jamie Cullum's $27^{\text {th }}$ May Instagram Live event, where user mimi_mfa commented “I finish my online piano lessons at 7 pm. Just in time!!" 38 These comments, and the thousands more that accompany them, demonstrate a willing audience anticipating online performance as an important and scheduled part of their evening's entertainment. It is interesting to note here that the online schedule has not chosen to augment itself for a captive audience by spreading performances across the whole spread of time available, but rather sticking to the established norms for traditional live music consumption by scheduling performances for an approximate 19:30 start time. This further adds credence to the notion 
of increased legitimation for the online stage by porting the behaviours of traditional liveness to that of its Covid replacement.

\section{Conclusion}

In this article, I have theorised that the government-imposed lockdown in the United Kingdom has created a pressure cooker environment, which has had a major effect on the enculturation status of online digital media. Although this paper has focused on the UK, the majority of the world has been through similar lockdown scenarios, and therefore it can be expected that many individuals throughout the world may have experienced this shift in much the same way.

The lockdowns connected to the Covid-19 crisis are unprecedented and come at a time when access to technology for both consumption and creation is both ubiquitous and affordable. While the changes in naturalisation, enculturation and legitimisation of the online stage have been accelerated during recent months, it must again must be stressed that these processes were not instigated by the Covid-19 pandemic. Yet, it is the effect of the pandemic on the rate of these processes - due to a convergence of factors, such as an established culture of amateur and live authenticities, the sudden need for supplementary revenue for artists, and an increase in free time for the majority of the populous - that makes this such a unique moment in history for the relationship between technology and performance in the UK.

With a surge of working musicians turning to the online stage in search of a much-needed source of income, along with a number of major festivals employing it as their main venue, the online stage received a dramatic increase in prominence through sudden social-media ubiquity and an almost overnight adoption by media institutions. As such, the online stage gained a status of enculturation among a prominent section of the UK out of the necessity for live entertainment. Yet, despite this enculturation, it remains unlikely that musicians and audiences will not welcome "classic liveness" back into their lives with open arms if and when full capacity returns. $\underline{39}$

By using contemporary, real word examples inspired by the unique circumstances of Covid-19, I have been able to explore how we can begin to understand the ways in which we think about the enculturation process, by marking out its parallels with authenticity as a personalised process of technology's acceptance as part of the media we consume. By separating naturalisation and enculturation, and understanding their functions at different points in the same process, we can begin to further explore the fascinating intersection between audience and technology within an increasingly digital world. 


\section{Bibliography}

Allen, Ethan. "Hi guys, I will be doing a FACEBOOK LIVE stream tonight at 7pm to kick off your evening." Facebook, March 28, 2020. https://www.facebook.com/ethan.allen.1481.

Altman, Rick. “Television/Sound.” In Studies in Entertainment: Critical Approaches to Mass

Culture, edited by Tania Modleski, 39-54. Bloomington and Indianapolis: Indiana University Press, 1986.

Auslander, Philip. “Digital Liveness: A Historico-Philosophical Perspective." PAJ: A Journal of

Performance and Art 34, no. 3(2012): 3-11.

Auslander, Philip. Liveness: Performance in a Mediatized Culture, $2^{\text {nd }}$ edition. London: Routledge, 2008.

BBC. “Big Weekend UK 2020: What To Expect From Our First Virtual

Festival." BBC, 2020. https://www.bbc.co.uk/programmes/articles/YMnDtXjlPbSS6q b7YrZM00/big= weekend-uk-2020-what-to-expect-from-our-first-virtual-festival.

BBC. “Coronavirus: PM Says Everyone Should Avoid Office, Pubs and Travelling." BBC, March 16, 2020. https://www.bbc.co.uk/news/uk-51917562.

Brøvig-Hanssen, Ragnhild, and Anne Danielsen. "The Naturalised and the Surreal: Changes in the Perception of Popular Music Sound." Organised Sound 18, no. 1 (2013): 71-80.

Bucher, Taina, and Anne Helmond. "The Affordances of Social Media Platforms." In The SAGE Handbook of Social Media, edited by Jean Burgess, Alice Marwick, and Thomas Poell, 233-253. London: SAGE Publications Ltd, 2018.

Burgess, Jean. "Hearing Ordinary Voices: Cultural Studies, Vernacular Creativity and Digital Storytelling." Continuum 20, no. 2 (2006): 201-214.

Burgess, Jean, and Joshua Green. YouTube: Online Video and Participatory Culture, $2^{\text {nd }}$ edition. Cambridge: Polity Press, 2018.

Couldry, Nick. "Liveness, 'Reality', and the Mediated Habitus From Television to the Mobile Phone." Communication Review 7, no. 4 (December 2004): 353-61. 
Flew, Terry. New Media: An Introduction, $3^{\text {rd }}$ edition. Melbourne: Oxford University Press, 2008.

Forbes. “The World's Top Earning YouTube Stars 2015.” Forbes, October 14, 2015.

https://www.forbes.com/pictures/gj $\underline{\text { dm45j}}$ ih/youtube-millionaires/\#4f8ede32629d.

Frith, Simon. Art Versus Technology: The Strange Case of Popular Music." Media, Culture \& Society 8 , no. 3 (1986): 263-279.

Gembris, Heiner. “The Development of Musical Abilities." In MENC Handbook of Music Cognition and Development, edited by Richard Cowell, 124-164. New York: Oxford University Press, 2006.

Google. "History of Monetization at YouTube." Accessed May 25, 2020.

https://sites.google.com/a/pressatgoogle.com/youtube5year/home/history-of-monetization-atyoutube.

Hagestedt, Betsy. "Popular Concert Recording and Actor Network Theory: An Examination of Pearl Jam and Participatory Culture on YouTube." Platforum: Journal of Graduate Students in Anthropology 15, (2017): 44-73.

Havas Media. “COVID-19 // Media Consumption Report Vol.1 // Havas Media UK POV.” March 25, 2020. https://www.slideshare.net/HavasWorldwide/covid19-media-behaviours-report-havas-mediauk-pov.

Hong, Seoyeon, Mi R. Jahng, Namyeon Lee, and Kevin R. Wise. "Do You Filter Who You Are?: Excessive Self-Presentation, Social Cues, and User Evaluations of Instagram Selfies." Computers in Human Behavior 104 (March 2020): 1-6.

IFPI. “Music Listening Report." IFPI, September 24, 2019. https://www.ifpi.org/wpcontent/uploads/2020/07/Music-Listening-2019-1.pdf.

Jenkins, Henry. Textual Poachers: Television Fans and Participatory Culture, $20^{\text {th }}$ anniversary edition. New York: Routledge, 2013.

Keen, Andrew. The Cult of the Amateur: How Blogs, MySpace, YouTube and the Rest of Today's UserGenerated Media Are Killing our Culture and Economy. London: Nicholas Brealey Publishing, 2008. Kindle.

Lardinois, Frederic. "YouTube Partners With ABC News To Offer Its First-Ever Live Stream Of The U.S. Presidential Debates." Tech Crunch, October 1, 2012. https://techcrunch.com/2012/10/01/youtubepartners-with-abc-news-to-offer-its-first-ever-live-stream-of-the-u-s-presidential-debates/. 
Lee, Carmen K. M. "Micro-Blogging and Status Updates on Facebook: Texts and Practices." In Digital Discourse: Language in the New Media, edited by Crispin Thurlow and Kristine Mroczek, 110-128. Oxford: Oxford University Press, 2011.

Live in The Living Room. "Live in the Living Room's Coronapolooza!." Facebook Event, May 2-3, 2020. https://www.facebook.com/events/688490308626226/.

McMorran, Callum. “The Sunday Sessions Live for the NHS.” Facebook Event, May 3, 2020.

https://www.facebook.com/events/d41d8cd9/the-sunday-sessions-live-for-thenhs/865598263914894/.

mimi_mfa. May 27, 2020. Comment on Jamie Cullum (@jamiecullum). “Hey everybody. I'm going to be live on Instagram tomorrow evening at 7pm BST. See you there. Jx." Instagram, May 27, 2020. https://www.instagram.com/p/CAtBfgUnn5X/?utm source=ig_web copy_link.

Moore, Allan. "Authenticity as Authentication." Popular Music 21, no. 2 (2002): 209-223.

Morrison, Steven J., Steven M. Demorest, and Laura A. Stambaugh. "Enculturation Effects in Music Cognition: The Role of Age and Music Complexity." Journal of Research in Music Education 56, no. 2 (2008): 118-129.

Nagy, Peter and Gina Neff. "Imagined Affordance: Reconstructing a Keyword For Communication Theory." Social Media + Society 1, no. 2 (July 2015): 1-9.

O’Reilly, Tim. "What is Web 2.0: Design Patterns and Business Models for the Next Generation of Software." Communications \& Strategies no. 65 (2007): 17-37.

Odell, Lillian. April 3, 2020. Comment on Ethan Allen. "Facebook live today at 7 pm." Facebook, April 3, 2020. https://www.facebook.com/plugins/post.php?

href=https\%3A\%2F\%2Fwww.facebook.com\%2Fethan.allen.1481\%2Fposts\%2F10220052299074285\&widt $\underline{\mathrm{h}=500}$.

Paul, Kari. “Twitter announces employees will be allowed to work from home 'forever'." The Guardian, May 12, 2020. https://www.theguardian.com/technology/2020/may/12/twitter-coronaviruscovid19-work-from-home.

Savage, Mark. "Coronavirus: Stars take part in One World: Together At Home concert." BBC, April 19, 2020. https://www.bbc.co.uk/news/entertainment-arts-52333890.

Southern, Matt. "Facebook Focusing on Live Streaming As Usage Spikes During COVID-19 Lockdowns." searchenginejournal.com, March 29, 
2020. https://www.searchenginejournal.com/facebook-focusing-on-live-streaming-as-usage-spikesduring-covid-19-lockdowns/357884/\#close.

Sparrow, Andrew, Lucy Campbell, and Kevin Rawlinson. "UK coronavirus: Boris Johnson announces strict lockdown across country - as it happened." The Guardian, March 24,

2020. https://www.theguardian.com/politics/live/2020/mar/23/uk-coronavirus-live-news-latest-

boris-johnson-minister-condemns-people-ignoring-two-metre-distance-rule-in-parks-as-very-selfish.

Strangelove, Michael. Watching YouTube: Extraordinary Videos by Ordinary People. Toronto: University of Toronto Press, 2011.

Thornton, Sarah. Club Cultures: Music, Media, and Subcultural Capital. Cambridge: Polity Press, 1995.

\section{Media Cited}

Allen, Ethan. “Tip Jar.” Facebook Live Stream, March 28,

2020. https://www.facebook.com/ethan.allen.1481/videos/10219981367021028.

\section{Biography}

Taran Harris is a PhD candidate at the University of Liverpool as well as a composer and classical singer in the North West of England.

His thesis looks at the effects of technology on the reception and creation on music in recorded, live and pedagogical settings.

\section{Footnotes}

1. Philip Auslander, "Digital Liveness: A Historico-Philosophical Perspective," PAJ: A Journal of Performance and Art 34, no. 3 (2012): 3-11. $\subseteq$ 
2. IFPI, "Music Listening Report," IFPI, September 24, 2019, https://www.ifpi.org/wpcontent/uploads/2020/07/Music-Listening-2019-1.pdf. $\doteq$

3.

For more on enculturation of television media, see Philip Auslander, Liveness: Performance in a Mediatized Culture, $2^{\text {nd }}$ ed. (London: Routledge, 2008);

Rick Altman, "Television/Sound," in Studies in Entertainment: Critical Approaches to Mass Culture, ed. Tania Modleski (Bloomington and Indianapolis: Indiana University Press, 1986). $\subseteq$

4.

Steven J. Morrison, Steven M. Demorest, and Laura A. Stambaugh, "Enculturation Effects in Music Cognition: The Role of Age and Music Complexity," Journal of Research in Music Education 56, no. 2 (2008): 118-129;

Heiner Gembris, "The Development of Musical Abilities," in MENC Handbook of Musical Cognition and Development, ed. Richard Colwell (Oxford University Press, 2006), 124-164;

Ragnhild Brøvig-Hanssen and Anne Danielsen, "The Naturalised and the Surreal: Changes in the Perception of Popular Music Sound," Organised Sound 18, no. 1 (2013): 71-80.

5. Sarah Thornton, Club Cultures: Music, Media, and Subcultural Capital (Cambridge: Polity Press. 1995), 28-29.

6. Auslander, "Digital Liveness," 7.

7. Allan Moore, "Authenticity as Authentication," Popular Music 21, no. 2 (2002): 221.

8. Matt Southern, "Facebook Focusing on Live Streaming As Usage Spikes During COVID-19 Lockdowns," searchenginejournal.com, March 29, 2020, https://www.searchenginejournal.com/facebook-focusing-on-live-streaming-as-usage-spikesduring-covid-19-lockdowns/357884/\#close. $\leftrightarrows$

9. Nick Couldry, "Liveness, 'Reality', and the Mediated Habitus From Television to the Mobile Phone," Communication Review 7, no. 4 (December 2004): 356-357.

10. Auslander, Liveness, 3.

11. Altman, “Television/Sound," $45 . \Leftarrow$

12. Jean Burgess and Joshua Green, YouTube: Online Video and Participatory

Culture, $2^{\text {nd }}$ ed. (Cambridge: Polity Press, 2018), 20. $匚$ 
13. Jean Burgess, “Hearing Ordinary Voices: Cultural Studies, Vernacular Creativity and Digital Storytelling," Continuum, 20, no. 2 (2006): 206.

14.

For scholarship on YouTube, see Burgess and Green, YouTube;

Andrew Keen, The Cult of the Amateur: How Blogs, MySpace, YouTube and the Rest of Today's UserGenerated Media Are Killing our Culture and Economy (London: Nicholas Brealey Publishing, 2008);

Michael Strangelove, Watching YouTube: Extraordinary Videos by Ordinary People (Toronto: University of Toronto Press, 2011).

15. Tim O'Reilly, "What is Web 2.0: Design Patterns and Business Models for the Next Generation of Software," Communications \& Strategies no. 65 (2007): 17.

16.

Terry Flew, New Media: An Introduction (Melbourne: Oxford University Press, 2008);

Betsy Hagestedt, "Popular Concert Recording and Actor Network Theory: An Examination of Pearl Jam and Participatory Culture on YouTube," PlatForum: Journal of Graduate Students in Anthropology 15 (2017): 49;

Henry Jenkins, Textual Poachers: Television Fans and Participatory Culture, $20^{\text {th }}$ anniversary ed. New York: Routledge, 2013), 46.

17. Burgess and Green, YouTube, vii. $\triangleq$

18. Ibid., 12. $\subseteq$

19. Keen, The Cult of the Amateur, chap 2, Kindle. $ヒ$

20. Ibid., chap $1 . \triangleq$

21.

Peter Nagy and Gina Neff, "Imagined Affordance: Reconstructing a Keyword For Communication Theory," Social Media + Society 1, no. 2 (July 2015) 1;

See also, Taina Bucher and Anne Helmond, "The Affordances of Social Media Platforms," in The SAGE Handbook of Social Media, ed. Jean Burgess, Alice Marwick, and Thomas Poell (London: SAGE Publications, 2017): 246.

22. Nagy and Neff, "Imagined Affordance," $5 . \pm$

23. Burgess and Green, YouTube, 12. $\subseteq$ 
24. Frederic Lardinois, "YouTube Partners With $A B C$ News To Offer Its First-Ever Live Stream Of The U.S. Presidential Debates," Tech Crunch, October 1, 2012, https://techcrunch.com/2012/10/01/youtube-partners-with-abc-news-to-offer-its-first-everlive-stream-of-the-u-s-presidential-debates $/ . \oplus$

25. Carmen K. M. Lee, "Micro-Blogging and Status Updates on Facebook: Texts and Practices," in Digital Discourse: Language in the New Media, ed. Crispin Thurlow and Kristine Mroczek (Oxford: Oxford University Press, 2011), 115. $\subseteq$

26. Simon Frith, "Art Versus Technology: The Strange Case of Popular Music," Media, Culture $\mathcal{E}$ Society 8, no. 3 (1986): 267.

27. Seoyeon Hong, Mi R. Jahng, Namyeon Lee, and Kevin R. Wise, "Do You Filter Who You Are?: Excessive Self-Presentation, Social Cues, and User Evaluations of Instagram Selfies," Computers in Human Behavior 104 (2020): $2 . \doteq$

28. Andrew Sparrow, Lucy Campbell, and Kevin Rawlinson, "UK Coronavirus: Boris Johnson Announces Strict Lockdown Across Country - As It Happened," The Guardian, March 24, 2020, https://www.theguardian.com/politics/live/2020/mar/23/uk-coronavirus-live-news-latestboris-johnson-minister-condemns-people-ignoring-two-metre-distance-rule-in-parks-as-veryselfish. $\doteq$

29.

Forbes, “The World's Top Earning YouTube Stars 2015," Forbes, October 14, 2015, https://www.forbes.com/pictures/gjdm45jih/youtube-millionaires/\#4f8ede32629d;

"History of Monetization at YouTube," Google, accessed May 25, 2020, https://sites.google.com/a/pressatgoogle.com/youtube5year/home/history-of-monetization-at-youtube. 30. BBC, "Coronavirus: PM Says Everyone Should Avoid Office, Pubs and Travelling," BBC, March 16, 2020, https://www.bbc.co.uk/news/uk-51917562.

31.

Ethan Allen, "Hi guys, I will be doing a FACEBOOK LIVE stream tonight at 7pm to kick off your evening," Facebook, March 28, 2020, https://www.facebook.com/photo/? fbid $=10219977462603420 \&$ set $=$ p.10219977462603420.

Note: this link has since been made private. $\bullet$

32. Ethan Allen, “Tip Jar," Facebook Live Stream, March 28, 2020, https://www.facebook.com/ethan.allen.1481/videos/10219981367021028. 
33.

Live in The Living Room, "Live in the Living Room's Coronapolooza!," Facebook Event, May 2-3, 2020, https://www.facebook.com/events/688490308626226/;

BBC, "Big Weekend UK 2020: What To Expect From Our First Virtual Festival, BBC, 2020, https://www.bbc.co.uk/programmes/articles/YMnDtXJlPbSS6qb7YrZM00/big-weekend-uk-2020what-to-expect-from-our-first-virtual-festival.

34. Mark Savage, "Coronavirus: Stars Take Part in One World: Together At Home Concert," BBC, April 19, 2020, https://www.bbc.co.uk/news/entertainment-arts-52333890.

35. Ibid. $\triangleq$

36. Havas Media, "COVID-19 // Media Consumption Report Vol.1 // Havas Media UK POV," March 25, 2020, https://www.slideshare.net/HavasWorldwide/covid19-media-behaviours-report-havasmedia-uk-pov. $\uplus$

37. Callum McMorran, “The Sunday Sessions Live for the NHS," Facebook Event, May 3, 2020, https://www.facebook.com/events/d41d8cd9/the-sunday-sessions-live-for-the$\underline{\text { nhs } / 865598263914894 / .} \doteq$

38.

Lillian Odell, April 3, 2020, comment on Ethan Allen, "Facebook live today at 7 pm," Facebook, April 3, 2020, https://www.facebook.com/plugins/post.php?

href=https\%3A\%2F\%2Fwww.facebook.com\%2Fethan.allen.1481\%2Fposts\%2F10220052299074285\&wi $\underline{\mathrm{dth}}=500$;

mimi_mfa, May 27, 2020, comment on Jamie Cullum (@jamiecullum), “Hey everybody. I'm going to be live on Instagram tomorrow evening at 7pm BST. See you there. Jx," Instagram, May 27, 2020, https://www.instagram.com/p/CAtBfgunn5X/?utm_source=ig_web_copy_link.

39. Auslander, Liveness, 61. 